\title{
INVESTIGATION OF THE RESIDUAL TROPOSPHERIC ERROR INFLUENCE ON THE COORDINATE DETERMINATION ACCURACY IN A SATELLITE LANDING SYSTEM
}

\author{
Oleksandr KUTSENKO (D) ${ }^{1}$, Svitlana ILNYTSKA (D) ${ }^{2 *}$, Valeriy KONIN (D) ${ }^{3}$ \\ ${ }^{1,2}$ Research and Training Center "Aerospace Center", National Aviation University, Kyiv, Ukraine \\ ${ }^{3}$ Air Navigation Department, National Aviation University, Kyiv, Ukraine
}

Received 18 May 2018; accepted 23 September 2018

\begin{abstract}
This paper presents the results of the investigation of the residual tropospheric error influence on coordinate determination in a GNSS landing system. The ICAO recommended methodology for residual tropospheric error calculation is taken as a basis for the present research. Special attention is paid to the troposphere refractivity index and troposphere scale height, which are derived from the well-known troposphere refraction MOPS model. A computer simulation is performed for them for the whole year and the northern hemisphere latitudes. Hardware in the loop simulation has been performed to complement the computer simulation study and investigate the situation with the residual tropospheric error calculation for the experimental GNSS satellites configuration. The experimental measurement session with a duration of about 9 hours is recorded to obtain the configuration of real navigation satellites The residual tropospheric error in meters is calculated for each navigation satellite visible during the experiment. The authors investigate the residual tropospheric error influence on the accuracy of the coordinates determined in the GNSS landing system.
\end{abstract}

Keywords: global navigation satellite system (GNSS), landing system, ground based augmentation system (GBAS), residual tropospheric error, refraction index, scale height, computer simulation.

\section{Introduction}

The Global Navigation Satellite System (GNSS) is a core technology that has led to the development of the Performance Based Navigation (PBN) concept. It is also the basis for future improvements in navigation services (International Civil Aviation Organization [ICAO], 2012a, 2016).

The aviation industry has embraced the ground based augmentation system (GBAS) owing to its multiple advantages, in particular, ability to meet the stringent requirements of the aviation community (system accuracy, continuity, availability, and integrity for the intended operation). Augmentation information is commonly provided for a local limited area, e.g., the vicinity of the airports (Hofmann-Wellenhof, Lichtenegger, \& Wasle, 2008). The GBAS is intended to support all types of approach, landing, departure, and surface operations, and may support en-route and terminal operations (ICAO, 2012a, 2012b). The use of the PBN and GNSS landing system (GLS) procedures will enhance the reliability and predictability of approaches to runways, thus increasing safety, accessibility, and efficiency (ICAO, 2016).

According to EUROCONTROL, the GBAS provides a cost-efficient solution, since only one ground station is needed to service multiple approaches to all runways at an airport. Its advanced procedures can directly support busy airports with capacity limitations, aiming to address noise issues and efficient arrival paths. The GBAS has gained international support as well as significant operational experience. It is now firmly positioned in the aviation navigation mix as the logical follow-on to the PBN in the precision approach phase of flight. Currently, GBAS Category I operations are implemented at the following airports: Bremen, Malaga, Frankfurt, and Zurich (EUROCONTROL, n.d.).

The typical GBAS consists of ground and airborne elements (Hofmann-Wellenhof et al., 2008). A GBAS ground subsystem typically includes $2-4$ reference GNSS receivers, ground processing facilities and a VHF data broadcast (VDB) transmitter (working at the frequency band

*Corresponding author. E-mail: ilnytskasv84@gmail.com 
108-117.975 MHz). The GBAS ground subsystem can support all the airborne subsystems within its coverage, providing the aircraft with approach data, corrections, and integrity information for the GNSS satellites in view (ICAO, 2012a, 2012b; RTCA, 2004).

\section{General regulations}

To obtain a navigation solution with the increased accuracy, the GBAS system corrects the pseudo-ranges measured at the airborne subsystem by means of information obtained from the ground subsystem. The correction of the pseudo-range for a given satellite is performed in the following way (ICAO, 2012b; RTCA, 2004):

$$
\begin{aligned}
& P R_{c o r}=P_{C S C}+P R C+R R C \times\left(t-t z_{-} \text {count }\right)- \\
& T C+c \times\left(\Delta t_{s v}\right)_{L 1} .
\end{aligned}
$$

Typically, the differential mode provides the maximum compensation of the tropospheric error in the pseudoranges due to the correlation of errors in the base and rover receiver. However, the significant differential altitude between the base (ground subsystem) and rover (airborne subsystem) receivers characterizes its implementation for aviation (GBAS). This causes the decorrelation of errors between them, and, therefore, the residual tropospheric error TC (1) increase. The airborne subsystem calculates it for a given satellite according to the following formula (ICAO, 2012b; RTCA, 2004):

$$
T C=N_{R} h_{0} \frac{10^{-6}}{\sqrt{0.002+\sin ^{2}(\Theta)}}\left(1-e^{\frac{-\Delta h}{h_{0}}}\right) .
$$

The physical meaning of the parameters used for the tropospheric error simulation according to Equation (2) is illustrated in Figure 1.

The aim of this article is to address the residual tropospheric error TC (2) calculation using the ICAO recommended methodology (ICAO, 2012b; RTCA, 2004) and then to investigate its influence on the accuracy of coordinate determination in the GNSS landing system. This article continues the research presented in (Kutsenko, Ilnytska, \& Konin, 2017). It extends the hardware in the loop

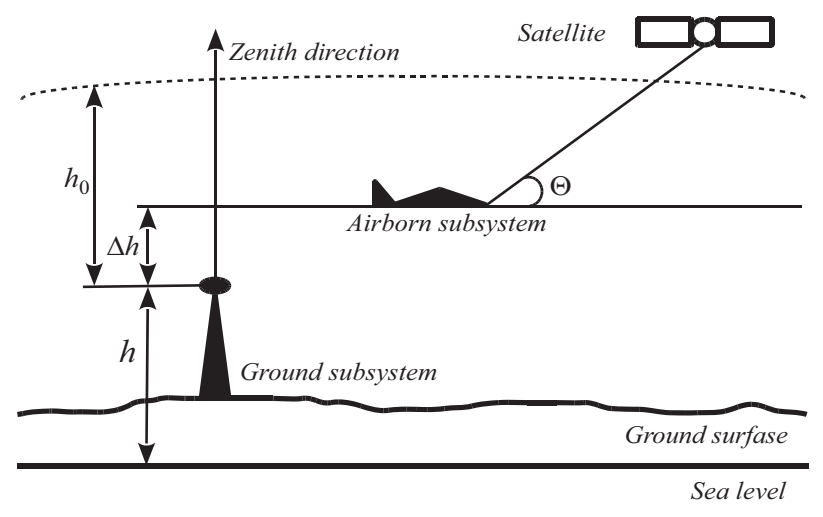

Figure 1. Schematic illustration of the parameters used for the tropospheric error simulation simulation part, providing comparison of the residual tropospheric error in meters for the difference of two altitudes between airborne and ground receivers. Additionally, this paper introduces the investigation of the influence of the residual tropospheric error on the determination of coordinates. The methodology of the residual tropospheric error investigation (ICAO, 2012b; RTCA, 2004) requires a number of parameters generated both by the airborne and ground sub-systems of the GBAS. First, it is necessary to consider the ways of deriving those parameters. Then, a more detailed study for different conditions should be carried out by means of corresponding computer simulations.

To investigate the residual tropospheric error calculation for a real navigation satellite configuration, and to estimate the error's influence on the accuracy of coordinates' determination, it is suggested to perform a longterm recording of GNSS data to be used as input simulation parameters.

\section{The proposed methodology for tropospheric error calculation and simulation}

\subsection{The basic methodology for the calculation of tropospheric parameters}

Based on the research results described in (Schüler, 2001), the methodology for the troposphere zenith delay, refraction index, and scale height simulation is proposed.

The troposphere zenith delay is the delay that occurs in the ground subsystem when the satellite is in zenith relative to the antenna of the ground subsystem. It is defined as follows:

$$
\Delta Z=10^{-6} \int_{h}^{\infty} N_{R}(H) d H=10^{-6} N_{R} h_{0} .
$$

The troposphere refraction index consists of dry and wet components:

$$
N_{R}=N_{d}+N_{w} .
$$

Similarly, for the zenith troposphere delay,

$$
\Delta Z=Z_{d}+Z_{w} .
$$

The components of the zenith troposphere delay are defined as follows:

$$
\begin{aligned}
& Z_{d}=10^{-6} \int_{h}^{\infty} N_{d}(H) d H=10^{-6} N_{d} h_{d}, \\
& Z_{w}=10^{-6} \int_{h}^{\infty} N_{w}(H) d H=10^{-6} N_{w} h_{w} .
\end{aligned}
$$

Substituting Equations (3), (6) and (7) into Equation (5) yields:

$$
10^{-6} N_{R} h_{0}=10^{-6} N_{d} h_{d}+10^{-6} N_{w} h_{w} .
$$

Taking into account Equation (4), from (8), it is possible to get the expression for the troposphere scale height:

$$
h_{0}=\frac{N_{d} h_{d}+N_{w} h_{w}}{N_{d}+N_{w}} .
$$


The model for defining the refraction index at sea level is known since the 50 -ies and, according to (HofmannWellenhof et al., 2008) or (Schüler, 2001), is expressed as follows:

$$
\begin{aligned}
& N_{d, 0}=k_{1} \frac{P_{0}}{T_{0}}, \\
& N_{w, 0}=k_{2} \frac{e_{0}}{T_{0}^{2}} .
\end{aligned}
$$

The partial pressure of water vapor at sea level can be defined from the following equation:

$$
e_{0}=e^{*} \frac{R H_{0}}{100 \%} E P^{\frac{L}{R_{e}}\left(\frac{1}{T^{*}}-\frac{1}{T_{0}}\right)} .
$$

There are a few models for defining the wet and dry refraction indexes, namely the Hopfield model (Hopfield, 1969), Saastamoinen model (Saastamoinen, 1972), Black model, model of New Brunswick University, GCAT, and MOPS models. These models have been reviewed in more detail in (RTCA, 2016; Schüler, 2001; Pershin, 2009). The Hopfield and MOPS models will be considered in the present paper.

The Hopfield model defines the dry and wet components of the troposphere refraction index as follows:

$$
\begin{aligned}
& \mathrm{N}_{\mathrm{d}}=N_{d, 0}\left[1-\frac{h}{h_{t r, d}}\right]^{4} ; \\
& \mathrm{N}_{\mathrm{w}}=N_{w, 0}\left[1-\frac{h}{h_{t r, w}}\right]^{4} \cdot \\
& \text { Here } h_{t r, d}=40136+148.72 \cdot(T-273.16), \\
& h_{t r, w}=7508+0.002421 \cdot \operatorname{EXP} \frac{T-273.16}{22.9}
\end{aligned}
$$

Equations (9)-(14) for the calculation of the troposphere scale height and refraction are presented in a slightly different way in (Warburton, 2010); however, those formulae imply the availability of meteorological data (surface temperature, static pressure, and relative humidity).

The MOPS model is more detailed (RTCA, 2016; Schüler, 2001). This model has been developed with the use of a huge amount of measurements of real troposphere parameters; therefore, it can represent a real situation. Although according to (Schüler, 2001), the accuracy characteristics of this model are worse, its advantage is the absence of requirements for the measured meteorological data. This might be beneficial in applications for unmanned aerial vehicles (UAV), as in (Kutsenko, Ilnytska, Kondratuik, \& Konin, 2017), where a simplified version of the GBAS is proposed.

Instead of the measured meteorological data, the meteorological parameters in the MOPS model are defined as:

$$
\xi(\varphi, D o Y)=\left\{P_{0}, T_{0}, e_{0}, \beta, \lambda\right\} .
$$

First of all, it is necessary to choose the table values of $\xi_{0}(\varphi)$ and $\Delta \xi(\varphi)$ that are closest to the latitude $\varphi$. Then, those meteorological parameters are corrected according to the latitude:

$$
\begin{aligned}
& \xi_{0}^{*}(\varphi)=\xi_{0}\left(\varphi_{i}\right)+\left[\xi_{0}\left(\varphi_{i+1}\right)-\xi_{0}\left(\varphi_{i}\right)\right] \cdot \frac{\varphi-\varphi_{i}}{\varphi_{i+1}-\varphi_{i}} \\
& \Delta \xi^{*}(\varphi)=\Delta \xi\left(\varphi_{i}\right)+\left[\Delta \xi\left(\varphi_{i+1}\right)-\Delta \xi\left(\varphi_{i}\right)\right] \cdot \frac{\varphi-\varphi_{i}}{\varphi_{i+1}-\varphi_{i}}
\end{aligned}
$$

Afterwards, correction according to the Day of the Year is applied:

$$
\begin{aligned}
& \xi(\varphi, D o Y)=\xi_{0}^{*}(\varphi)-\Delta \xi^{*}(\varphi) . \\
& \cos \left[\frac{2 \pi\left(D o Y-D o Y_{0}\right)}{365.25}\right] .
\end{aligned}
$$

In the next step, the meteorological parameters for the specified height should be defined.

\subsection{Calculation and simulation of troposphere refraction index components}

The temperature in the troposphere can be approximated linearly using the temperature lapse rate (Schüler, 2001):

$$
T(H)=T_{0}-\beta H \text {. }
$$

Now it is possible to define the pressure. The equation for hydrostatic equilibrium follows from the ideal gas laws of Gay-Lussac and Boyle-Mariotte and can be expressed in differential form as:

$$
d P=-g \cdot \rho \cdot d H \text {. }
$$

The density is related with pressure in the following way:

$$
P(H)=\rho \cdot R_{d} \cdot T(H) .
$$

This leads to the differential equation:

$$
\frac{d P}{P(H)}=-\frac{g}{R_{d} T(H)} \cdot d H .
$$

Taking into account (18), the differential equation (19) can be solved by integration with respect to height from the mean sea level to the ground subsystem:

$$
\begin{aligned}
& \int_{P_{0}}^{P} \frac{1}{P(H)} \cdot d P=-\frac{g}{R_{d}} \int_{0}^{h} \frac{1}{T_{0}-\beta H} \cdot d H, \\
& P=P_{0} \cdot\left(\frac{T_{0}-\beta h}{T_{0}}\right)^{\frac{g}{R_{d} \beta}} .
\end{aligned}
$$

Taking into account the abovementioned calculations, we obtain the following expression for the partial pressure of water vapor:

$$
e=e_{0} \cdot\left(\frac{P}{P_{0}}\right)^{\lambda+1}=e_{0} \cdot\left(\frac{T_{0}-\beta h}{T_{0}}\right)^{\frac{g(\lambda+1)}{R_{d} \beta}} .
$$


After substituting the meteorological parameters obtained above by Equations (10) and (11), it is possible to define the dry and wet refraction indices:

$$
\begin{aligned}
& N_{d}=k_{1} \frac{P}{T}=k_{1} P_{0}\left(\frac{T_{0}-\beta h}{T_{0}}\right)^{\frac{g}{R_{d} \beta}} \cdot \frac{1}{T_{0}-\beta h}= \\
& k_{1} \frac{P_{0}}{T_{0}}\left(\frac{T_{0}-\beta h}{T_{0}}\right)^{\frac{g}{R_{d} \beta}} \cdot \frac{T_{0}}{T_{0}-\beta h} ; \\
& N_{w}=k_{2} \frac{e}{T^{2}}=k_{2} e_{0}\left(\frac{T_{0}-\beta h}{T_{0}}\right)^{\frac{g(\lambda+1)}{R_{d} \beta}} \cdot \frac{1}{\left(T_{0}-\beta h\right)^{2}}= \\
& k_{2} \frac{e_{0}}{T_{0}^{2}}\left(\frac{T_{0}-\beta h}{T_{0}}\right)^{\frac{g(\lambda+1)}{R_{d} \beta}} \cdot\left(\frac{T_{0}}{T_{0}-\beta h}\right)^{2} ; \\
& N_{w}=k_{2} \frac{e_{0}}{T_{0}^{2}}\left(1-\frac{\beta h}{T_{0}}\right)^{\left(\frac{g(\lambda+1)}{R_{d} \beta}-2\right)} .
\end{aligned}
$$

A computer simulation has been performed for the parameters defined according to equations (24) and (25) for the whole year period and latitude ranges of $0-90^{\circ}$. The results of the simulation are presented in Figures 2 and 3. In the figures, the following designations are used: abscissa axis stands for months, ordinate axis - latitude (degrees), and the gradient depicts the dry and wet components of the troposphere refraction index $(\mathrm{mm} / \mathrm{km})$ respectively.

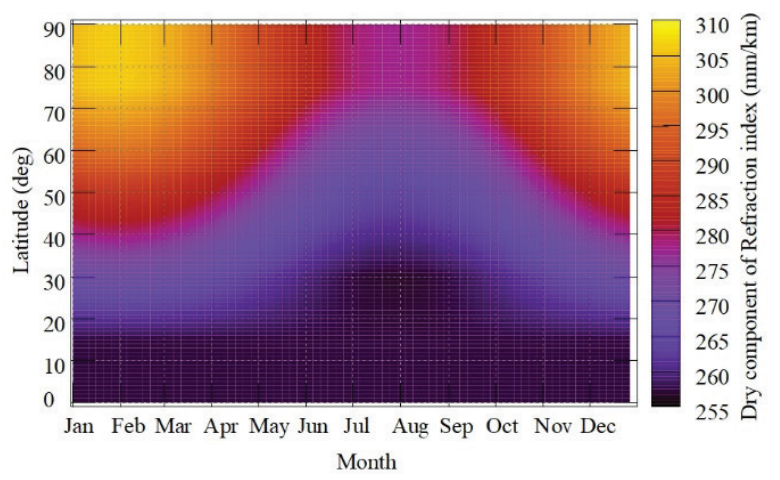

Figure 2. Simulation of the dry component of the troposphere refraction index

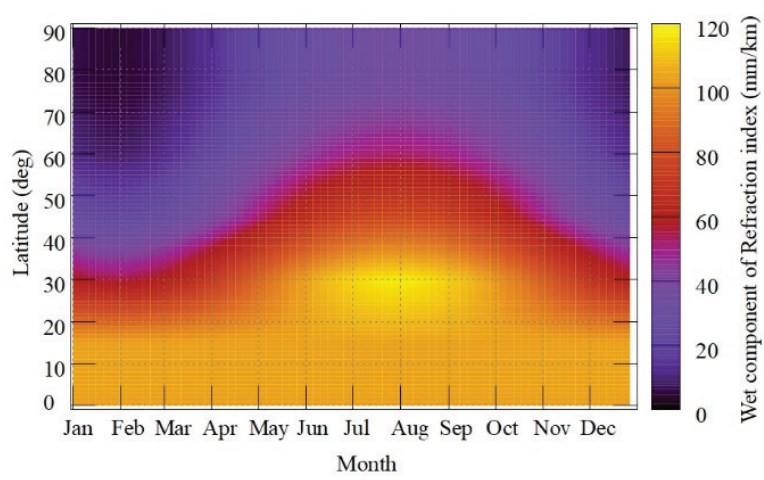

Figure 3. Simulation of the wet component of the troposphere refraction index
As seen in Figure 2, the dry refraction index $N_{d}$ reaches its maximal value, which is about $320 \mathrm{~mm} / \mathrm{km}$ for the latitudes $80-90^{\circ}$ in late January, and a minimum value, which is about $260 \mathrm{~mm} / \mathrm{km}$ for the latitudes $20-30^{\circ}$ in early August. Near the equator and up to $15^{\circ}$, it has low values. In contrast, the wet refraction index $N_{w}$ (Figure 3) reaches the peak minimal value, which is about $0 \mathrm{~mm} /$ $\mathrm{km}$, for the latitudes $80-90^{\circ}$ in late January, and a maximal value of $140 \mathrm{~mm} / \mathrm{km}$ for the latitudes $20-30^{\circ}$ in early August. Near the equator and up to $15^{\circ}$, it has high values.

\subsection{Calculation and simulation of troposphere scale height components}

Equation (6) can be integrated after substituting the dry component of the refraction index, previously obtained in equation (24), into it to obtain the dry component of the troposphere zenith delay:

$$
Z_{d}=10^{-6} k_{1} \frac{P_{0} R_{d}}{g}\left(1-\frac{\beta}{T_{0}} h\right)^{\frac{g}{R_{d} \beta}} .
$$

As a result, the height of the dry component of the troposphere scale height is defined using Equation (6):

$$
\begin{aligned}
& h_{d}=\frac{Z_{d}}{10^{-6} N_{d}}= \\
& \frac{10^{-6} k_{1} P_{0} R_{d} T_{0}\left(1-\frac{\beta}{T_{0}} h\right)^{\frac{g}{R_{d} \beta}}}{10^{-6} g k_{1} P_{0}\left(1-\frac{\beta}{T_{0}} h\right)^{\frac{g}{R_{d} \beta}-1}} .
\end{aligned}
$$

After simplification, we obtain the following:

$$
h_{d}=\frac{R_{d}}{g}\left(T_{0}-\beta h\right) \text {. }
$$

Equation (7) can be integrated after substituting the wet component of the refraction index, previously obtained in Equation (25), into it to obtain the wet component of the troposphere zenith delay:

$$
\begin{aligned}
& Z_{w}=10^{-6} k_{2} \frac{e_{0} R_{d}}{T_{0}\left(g(\lambda+1)-R_{d} \beta\right)} . \\
& \left(1-\frac{\beta}{T_{0}} h\right)^{\frac{g(\lambda+1)}{R_{d} \beta}-1} .
\end{aligned}
$$

Afterwards, we define the wet component of the troposphere scale height using Equation (7), and, after some simplifications, we obtain the following:

$$
h_{w}=\frac{R_{d}}{g(\lambda+1)-R_{d} \beta}\left(T_{0}-\beta h\right)
$$

A computer simulation has been performed for the dry and wet components of the troposphere scale height $\left(h_{d}\right.$, $h_{w}$ ) for the whole year period, latitude ranges of $0-90^{\circ}$, and the height of a ground subsystem of about $120 \mathrm{~m}$. The simulation results are presented in Figures 4 and 5 . 


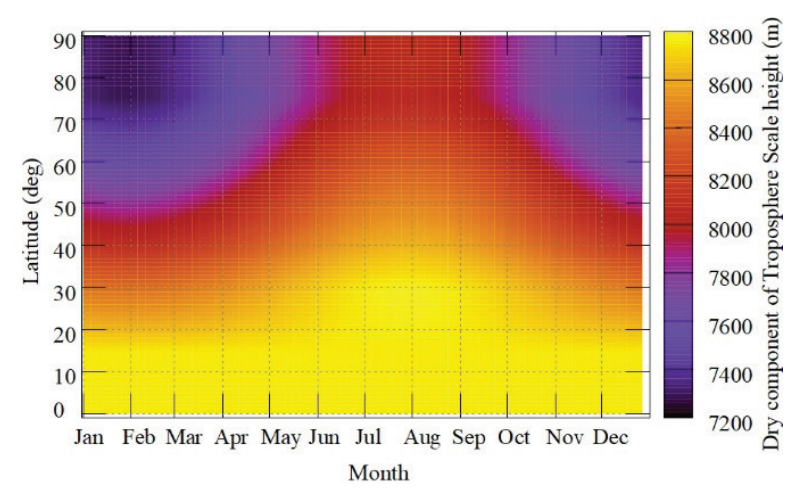

Figure 4. Simulation of the dry component of the troposphere scale height

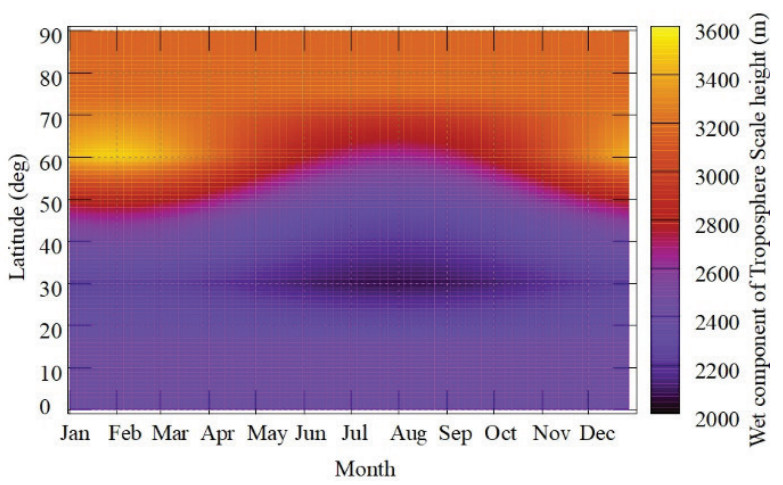

Figure 5. Simulation of the wet component of the troposphere scale height

The designations for the abscissa and ordinate axis are the same here, as for Figures 2 and 3, but the gradient here depicts the dry and wet components of the troposphere scale height $(\mathrm{m})$ respectively.

As seen in Figure 4, the dry component of the troposphere scale height $h_{d}$ reaches the peak minimal value, which is about $7200 \mathrm{~m}$ for the latitudes $80-90^{\circ}$ in late January, and the maximal value of $9000 \mathrm{~m}$ for the latitudes $20-30^{\circ}$ in early August. Near the equator and up to $15^{\circ}$, the values remain high. In contrast, the wet component of the troposphere scale height $h_{w}$ (Figure 5) reaches the peak maximal value, which is about $3600 \mathrm{~m}$ for the latitude $60^{\circ}$ in late January, and the minimal value of $2000 \mathrm{~m}$ for the latitude $30^{\circ}$ in early August.

\subsection{Troposphere refraction index and scale height simulation}

Based on the results presented in the previous subsection, a computer simulation has been performed for the troposphere refraction index $N_{R}$ and scale heigh $h_{0}$ for the whole year period, latitude ranges $0-90^{\circ}$, and the height of a ground subsystem of about $120 \mathrm{~m}$. The results of the simulation are presented in Figures 6 and 7. The designations for the abscissa and ordinate axis are the same here as for the Figures 2 and 5, and the gradient depicts the troposphere refraction index $(\mathrm{mm} / \mathrm{km})$ and scale height (m) respectively.

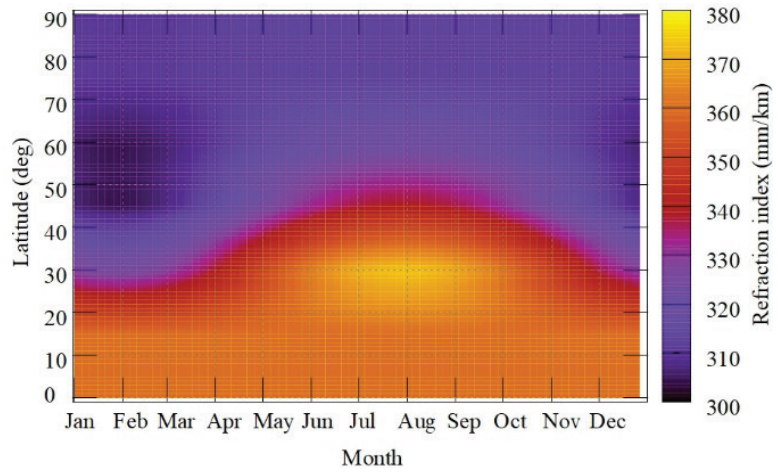

Figure 6. Simulation of the troposphere refraction index

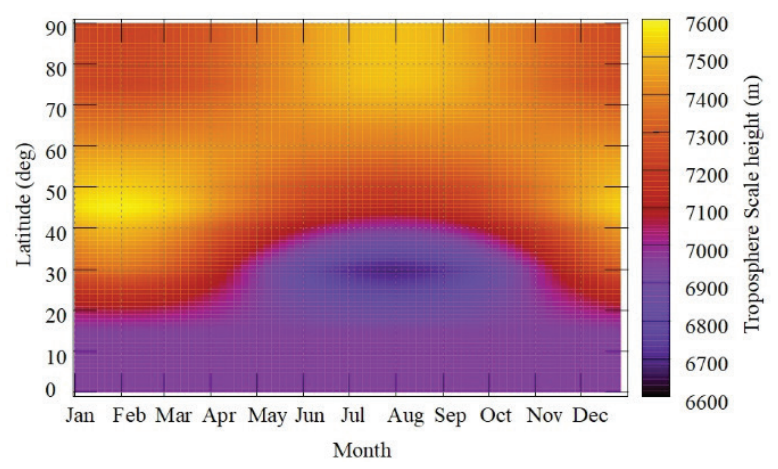

Figure 7. Simulation of the troposphere scale height

As seen in Figure 6, the troposphere refraction index $N_{R}$ reaches the peak minimal value, which is about $3100 \mathrm{~mm} / \mathrm{km}$ at the latitude $45^{\circ}$ in late January, and the maximal value of $400 \mathrm{~mm} / \mathrm{km}$ at the latitude $30^{\circ}$ in early August. The troposphere scale height $h_{0}$ (Figure 7), in contrast, reaches the peak maximal value, which is about $7600 \mathrm{~m}$ for the latitude $45^{\circ}$ in late January, and the minimal value of $6500 \mathrm{~m}$ for the latitude $30^{\circ}$ in early August.

\subsection{Residual tropospheric error simulation}

Based on the simulation results for the troposphere refraction index $N_{R}$ and troposphere scale height $h_{0}$, presented in Figures 6 and 7, the residual tropospheric error can be simulated for any navigation satellite and specified altitude difference between airborne and ground subsystems on any day of the year (Figure 8).

The abscise axis in Figure 8 includes all possible values of the navigation satellite elevation angles. The ordinate axis reflects the dependence of the residual tropospheric error on the navigation satellite elevation angles and altitude difference between airborne and ground subsystems, simulated according to Equation (2). The gradient depicts the altitude difference between airborne and ground subsystems in meters. The choice of altitude difference values is substantiated by the corresponding requirements laid out in (ICAO, 2012b; RTCA, 2004), which specify that the GBAS coverage in the vertical plane is between $30 \mathrm{~m}$ 


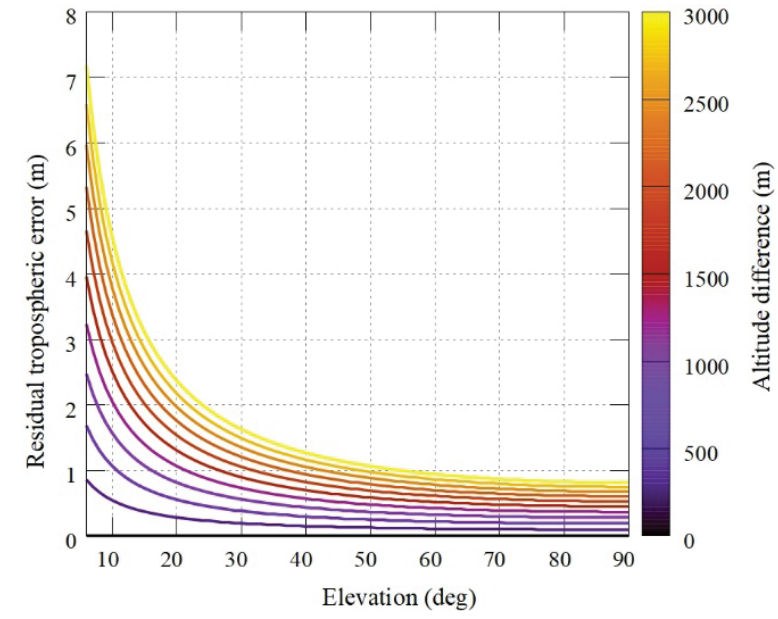

Figure 8. The dependence of residual tropospheric error on the navigation satellite elevation angle and altitude difference between airborne and ground subsystems

$(100 \mathrm{ft})$ and $3000 \mathrm{~m}(10000 \mathrm{ft})$. The values of $N_{R}(h)$ and $h_{0}(h)$ needed in Equation (2) were calculated according to Equations (4) and (9) for mid-May in the location of Kyiv to reflect the experiment that was performed and is described in greater detail in the next subsection.

\section{Hardware-in-the-loop simulation of the residual tropospheric error for an experimental GNSS satellite configuration}

To complement the computer simulation study and calculate the residual tropospheric error for an experimental configuration of GNSS satellites, a hardware-inthe-loop simulation has been performed. The facilities of the "Global navigation satellite systems experimental monitoring complex" of the National Aviation University (Kyiv), which belongs to the objects of National Heritage of Ukraine, were used (Cabinet of Ministers of Ukraine, 2013). Its geographical coordinates are $50^{\circ} 26^{\prime} \mathrm{N}$ latitude and $30^{\circ} 25^{\prime} \mathrm{E}$ longitude and its height above sea level is $120 \mathrm{~m}$. The complex houses different high quality GNSS receivers and antennas from NovAtel Inc. (NovAtel Inc., n.d.), among which are the GNSS receiver DL-4plus and antenna GPS-702-GG, which were used during the 9-hour measurement session in mid-May.

To determine the navigation satellite positions, we used the ephemeris data obtained from the measurement session according to the methodology presented in ISGPS-200 (Global Positioning Systems Directorate, 2016). The reference coordinates of the antenna were calculated from the recorded raw data by means of a specialized GNSS post-processing software package - the GrafNav/ GrafNet 8.70 by Waypoint Inc. (NovAtel Inc., 2018).

The residual tropospheric error for each navigation satellite observable during the experimental measurement session has been calculated according to equation (2). The sky plots of the navigation satellite configuration during

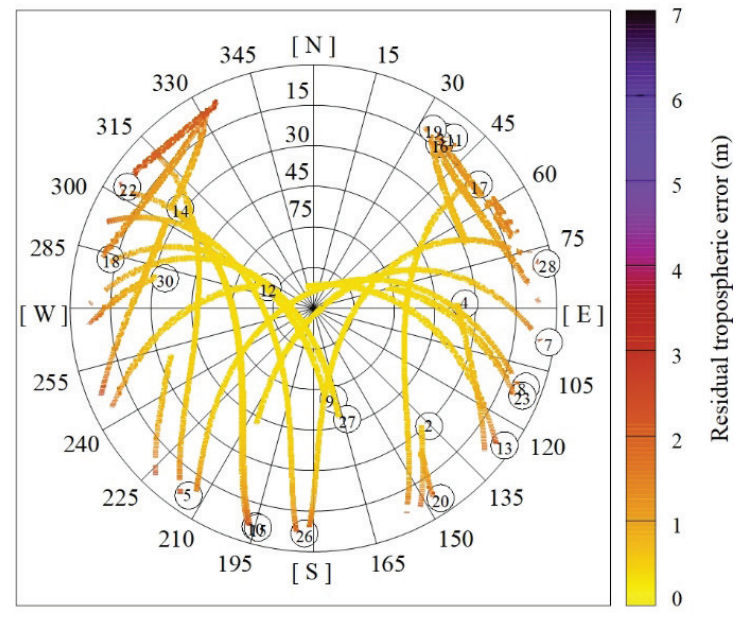

Figure 9. Simulation of the residual tropospheric error in meters (GBAS mode). Altitude difference $1000 \mathrm{~m}$

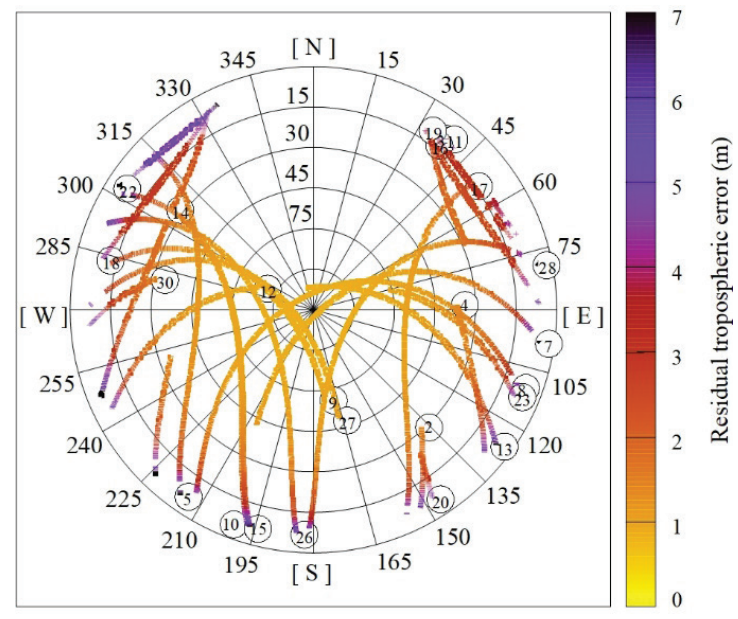

Figure 10. Simulation of the residual tropospheric error in meters (GBAS mode). Altitude difference $3000 \mathrm{~m}$

the experiment are presented in Figures 9 and 10, where the value of the residual tropospheric error in meters is depicted by means of a color gradient. Figure 9 illustrates the altitude difference between airborne and ground subsystems of 1000 m, and Figure 10 - a 3000 m difference. As observed in Figures 9 and 10, the sky plots are identical, differing only by the value of the residual tropospheric error obtained during simulation. It is evident that the value of the residual tropospheric error essentially depends on the elevation angle of the GPS satellite and reaches near zero values in zenith, tends to increase at elevation angles 30 and lower, and up to $7 \mathrm{~m}$ near the horizon for the altitude difference between airborne and ground subsystems of $3000 \mathrm{~m}$.

Figures 9 and 10 also illustrate that navigation satellites located closer to the North have higher values of the residual tropospheric error than the ones located closer to the South. This can be explained by the features of the navigation satellite orbits and the receiver's location during the described measurement session. 


\section{Investigation of the residual tropospheric error's influence on the coordinate determination accuracy in the GNSS landing system}

Taking into account what is mentioned above, it is sensible to consider the influence of the residual tropospheric error on the accuracy of the coordinates in the horizontal and vertical planes.

First, we need to determine the influence of the residual tropospheric error on the accuracy of the calculated coordinates in the ECEF reference frame $\left[T C_{X}^{E}, T C_{Y}^{E}, T C_{Z}^{E}\right]^{T}$. To do this, the vector containing the residual tropospheric errors $T C_{i}$ for each $i$-th $(i=1 \ldots N)$ visible navigation satellite is multiplied by the projection matrix $P$, of a size [Nx3]. This matrix projects the values aligned with the lines between the receiver and each observable navigation satellite in the ECEF reference frame.

$$
\left[\begin{array}{c}
T C_{X}^{E} \\
T C_{Y}^{E} \\
T C_{Z}^{E}
\end{array}\right]=P \times\left[\begin{array}{l}
T C_{1} \\
\vdots \\
T C_{i} \\
\vdots \\
T C_{N}
\end{array}\right] .
$$

The row of this matrix is as follows:

$$
P_{i}=\left[\begin{array}{ccc}
\frac{X_{R}-X_{S_{i}}}{R_{i}} & \frac{Y_{R}-Y_{S_{i}}}{R_{i}} & \frac{Z_{R}-Z_{S_{i}}}{R_{i}}
\end{array}\right] .
$$

Here $X_{R}, Y_{R}, Z_{R}$ are obtained from the GrafNav/GrafNet software package (NovAtel Inc., 2018); $X_{S_{i}}, Y_{S_{i}}, Z_{S_{i}}$ are obtained from the ephemeris according to the methodology presented in (Global Positioning Systems Directorate, 2016; ICAO, 2016). The distance between the receiver and the $i$-th navigation satellite is calculated as follows:

$$
R_{i}=\sqrt{\left(X_{R}-X_{S_{i}}\right)^{2}+\left(Y_{R}-Y_{S_{i}}\right)^{2}+\left(Z_{R}-Z_{S_{i}}\right)^{2}} .
$$

Afterwards, the influence of the residual tropospheric error on the accuracy of the calculated ENU coordinates can be obtained by multiplying the vector obtained above $\left[T C_{X}^{E}, T C_{Y}^{E}, T C_{Z}^{E}\right]^{T}$ on the corresponding transformation matrix (Grewal, Andrews, \& Bartone, 2013, p. 517):

$$
\left[\begin{array}{c}
T C_{E} \\
T C_{N} \\
T C_{U}
\end{array}\right]=\left[\begin{array}{ccc}
-S \lambda_{R} & C \lambda_{R} & 0 \\
-S \varphi_{R} C \lambda_{R} & -S \varphi_{R} S \lambda_{R} & C \varphi_{R} \\
C \varphi_{R} C \lambda_{R} & C \varphi_{R} S \lambda_{R} & S \varphi_{R}
\end{array}\right] \times\left[\begin{array}{c}
T C_{X}^{E} \\
T C_{Y}^{E} \\
T C_{Z}^{E}
\end{array}\right] .
$$

Here $\varphi_{R}, \lambda_{R}$ are obtained from the GrafNav/GrafNet software package (NovAtel Inc., 2018).

Finally, the obtained horizontal $T C_{H}=$ $\sqrt{\left(T C_{E}\right)^{2}+\left(T C_{N}\right)^{2}}$ and vertical $T C_{V}=\left|T C_{U}\right|$ components of the residual tropospheric error's influence on the accuracy of the coordinates are presented in Figures 11 and 12 . The color gradient here depicts the altitude difference between airborne and ground subsystems in meters. The choice of these altitude difference values is substanti-

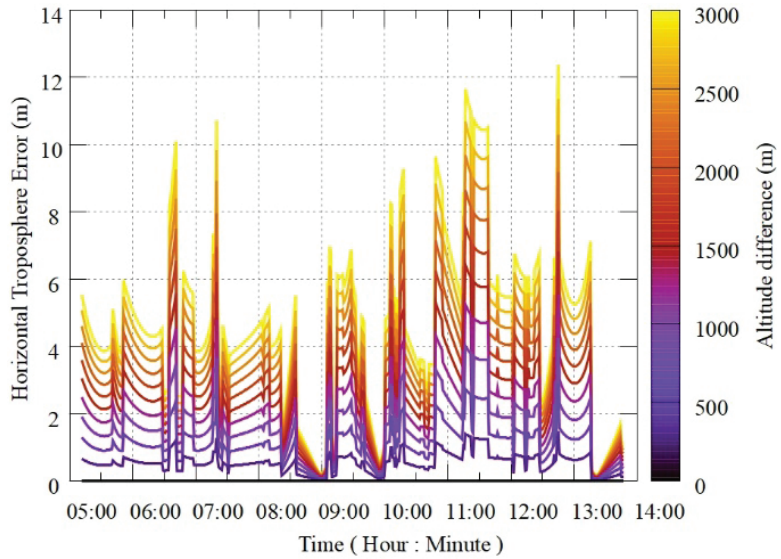

Figure 11. Horizontal component of the residual tropospheric error's influence on coordinate determination

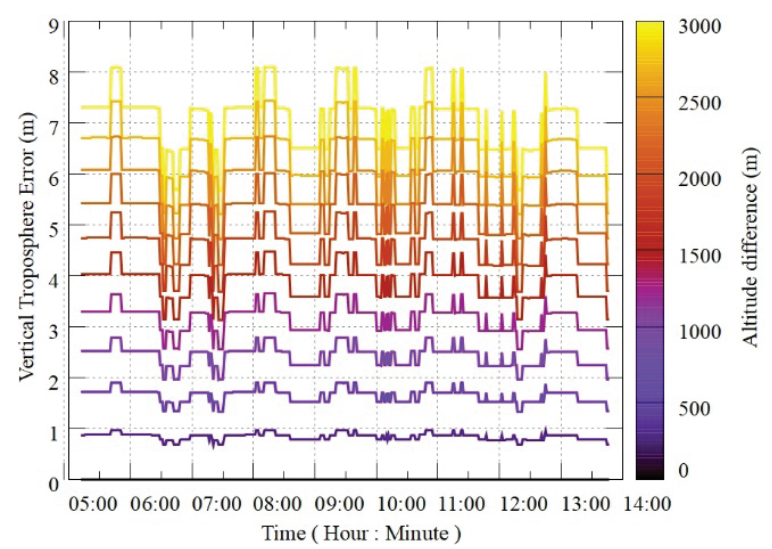

Figure 12. Vertical component of the residual tropospheric error's influence on coordinate determination

ated by the GBAS coverage in the vertical plane (ICAO, 2012b; RTCA, 2004), as mentioned in the previous subsection.

The plots are analysed in greater detail. For a $3000 \mathrm{~m}$ altitude difference between airborne and ground subsystems, the residual tropospheric error on coordinate determination reaches $13 \mathrm{~m}$ in the horizontal and $9 \mathrm{~m}$ in the vertical planes, and, for a $1000 \mathrm{~m}$ altitude difference, reaches $6 \mathrm{~m}$ for the horizontal and $4 \mathrm{~m}$ for the vertical planes.

As seen in Figures 11 and 12, the vertical component of the residual tropospheric error, in general, has higher values, but a smoother shape in comparison with the horizontal component. The higher values of the vertical component can be explained as follows. The residual troposphere correction $T C$, calculated according to equation (2), highly depends on the $\Delta h$ (the difference in altitude between airborne and ground subsystems). Therefore, after the transformation according to the relations (31-32) to the ENU coordinate frame, it naturally has a higher impact on the vertical component $T C_{U}$. Due to this, it is 
reasonable to investigate the influence of the $\Delta h$ on the residual tropospheric error.

It is also notable that the horizontal component of the residual tropospheric error (Figure 11) varies significantly with time in comparison with the vertical one (Figure 12). This happens because of the geometry of the visible satellites with respect to the user's position varies more in the horizontal plane. This is highly related with a measure of instantaneous geometry, i.e., the delusion of precision in the horizontal and vertical planes (HDOP and VDOP factors), as described in (Hofmann-Wellenhof et al., 2008).

When analysing Figure 11 in greater detail, it is evident that, at some moments in time (for example, between 8:00 and 10:00), there were cases when the horizontal component of the residual tropospheric error's influence on coordinate determination had zero values, while this was not observed for the vertical component. This can be explained by the particular geometry of the satellites at some moments in time, when the residual tropospheric error $T C$ from each visible satellite compensated each other. After the transformation of $T C$ according to the relations (31-32) to the ENU coordinate frame, it resulted in zero values for the East and North components.

\section{Conclusions}

The International Civil Aviation Organization (ICAO) has adopted the concept of a satellite based landing system of aircraft that involves determining the troposphere correction in a differential mode. The authors have obtained the results of an investigation pertaining to the residual tropospheric error's influence on the determination of coordinates in the GNSS landing system. The methodology for calculating the residual tropospheric error, performed by an airborne subsystem of the GBAS according to the recommendations of ICAO (ICAO, 2012b; RTCA, 2004), has been taken as the basis for the research.

Special attention has been paid to the troposphere refractivity index and troposphere scale height, which are calculated at the ground subsystem and transmitted to the aircraft through a communication channel. Those parameters have been derived from the well-known tropospheric delay MOPS model (RTCA, 2016; Schüler, 2001). The reason for choosing the MOPS instead of the Hopfield model (Schüler, 2001; Hofmann-Wellenhof et al., 2008) is mainly the absence of requirements for the measured meteorological data.

A computer simulation has been performed for the troposphere refractivity index and scale height, using the preliminary data obtained for their dry and wet components for the whole year and northern hemisphere latitudes.

A hardware-in-the-loop simulation has been performed to complement the computer simulation study and investigate the situation with the residual tropospheric error calculation for an experimental configuration of GNSS satellites. An experimental measurement session, which lasted approximately 9 hours, has been recorded using the facilities of the "Global navigation satellite systems experimental monitoring complex" of the National Aviation University in Kyiv. The data obtained during this experiment provided the authors with a real navigation satellite configuration. The residual tropospheric error in meters has been calculated for each navigation satellite visible during the experiment for two cases of altitude difference between the airborne and ground subsystems of the GBAS. The results have been presented as skyplots. Finally, the influence of the residual tropospheric error on the accuracy of coordinate determination in the GNSS landing system has been investigated for ten different cases of altitude difference between the airborne and ground subsystems of the GBAS.

\section{References}

Cabinet of Ministers of Ukraine. (2013). Pro vidnesennya naukovikh ob'€ktiv do takikh, shcho stanovlyat' natsional'ne nadbannya [Decree from 28.08.2013 \# 650-p. About referring of scientific objects as a national heritage. "Experimental Complex of Monitoring of Global Navigation Satellite Systems of National Aviation University"]. Retrieved 16 May 2018 from http://zakon2.rada.gov.ua/laws/show/650-2013$\% \mathrm{D} 1 \% 80$

Global Positioning Systems Directorate. (2016). Global Positioning Systems Directorate, System engineering and integration, Interface specification IS-GPS-200. NAVSTAR GPS Space Segment / Navigation User Segment Interfaces. Retrieved 16 March 2018 from https://www.gps.gov/technical/icwg/IRNIS-200H-001+002+003_rollup.pdf

Grewal, M. S., Andrews, A. P., \& Bartone, C. G. (2013). Global navigation satellite systems, Inertial Navigation, and Integration (3rd ed.). New Jersey, Hoboken: John Wiley \& Sons, Inc. (603 p.)

EUROCONTROL. (n.d.). Ground-Based Augmentation System (GBAS). Retrieved 16 May 2018 from http://www.eurocontrol. int/gbas

Hofmann-Wellenhof, B., Lichtenegger, H., \& Wasle, E. (2008). GNSS - Global Navigation Satellite Systems. GPS, Glonass, Galileo and more. Wien: Springer-Verlag press. https://doi.org/10.1007/978-3-211-73017-1

Hopfield, H. S. (1969). Two-Quartic tropospheric refractivity profile for correcting satellite data. Journal of Geophysical Research, 74(18), 4487-4499. https://doi.org/10.1029/JC074i018p04487

International Civil Aviation Organization. (2016). Global Air Navigation Plan 2016-2030 (ICAO Doc 9750-AN/963). (5 ed.). Retrieved 16 May 2018 from https://www.icao.int/ airnavigation/Documents/GANP-2016-interactive.pdf

International Civil Aviation Organization. (2012a). GNSS manual for technical introduction of mandatory GNSS operations (ICAO Doc 9849) (2d ed.). Retrieved 16 May 2018 from https:/www.icao.int/Meetings/anconf12/Documents/ Doc.\%209849.pdf

International Civil Aviation Organization (2012b). Aeronautical Telecommunications. Annex 10 to the Convention on International Civil Aviation (Vol. 1, 6 ed.). Retrieved 16 May 2018 from https://www.theairlinepilots.com/forumarchive/ quickref/icao/annex10.1.pdf

Kutsenko, O. V., Ilnytska, S. I., \& Konin, V. V. (2017, May 17). Troposphere parameters calculation and residual error modeling for GNSS landing system. In 20th Conference for 
Junior Researchers "Science - Future of Lithuania" Transport Engineering and Management, Vilnius, Lithuania (pp. 63-68). Retrieved 26 March 2018 from http://jmk.transportas.vgtu.lt/ index.php/tran2017/tran2017/paper/viewFile/122/145

Kutsenko, O. V., Ilnytska, S. I, Kondratuik, V. M., \& Konin, V. V. (2017, October 17-19). Unmanned aerial vehicle position determination in GNSS landing system. In 2017 IEEE 4th International Conference Actual Problems of Unmanned Aerial Vehicles Developments (APUAVD), Kyiv, Ukraine (pp. 79-84). IEEE. https://doi.org/10.1109/APUAVD.2017.830878

NovAtel Inc. (n.d.). High Precision GNSS Receivers. Retrieved 16 May 2018 from https://www.novatel.com/products/gnss-receivers/

NovAtel Inc. (2018). Waypoint products group: A NovAtel precice postioning product GrafNav / GrafNet GarfNav Static. Software Version 8.70 User Manual, REV 4. (Publication No. OM-20000165). Retrieved 19 March 2018 from https:// www.novatel.com/assets/Documents/Waypoint/Downloads/ GrafNav-GrafNet-User-Manual-870.pdf

Pershin, D. Yu. (2009). Comparative analysis of tropospheric delay models in precise point positioning in satellite navigation systems GLONAS/GPS”. NGU Proceedings. Information Technologies Series, 7(1), 84-91. Retrieved 19 May 2018 from https://cyberleninka.ru/ article/v/sravnitelnyy-analiz-modeley-troposfernoy-zaderzhki-vzadache-opredeleniya-mestopolozheniya-vysokoy-tochnosti-vsputnikovyh (in Russian).
RTCA. (2004). Minimum Aviation System Performance Standards for the Local Area Augmentation System (LAAS) (RTCA DO245A). Retrieved 16 March 2018 from https://standards. globalspec.com/std/11988/rtca-do-245

RTCA. (2016). Minimum Operational Performance Standards for Global Positioning System/Satellite-Based Augmentation System Airborne Equipment (RTCA DO-229E). Retrieved 26 March 2018 from https://standards.globalspec.com/ std/10072442/rtca-do-229

Saastamoinen, J. (1972). Atmospheric correction for the troposphere and stratosphere in radio ranging of satellites. In S. W. Henriksen, A. Mancini, \& B. H. Chovitz (Eds.), The use of Artificial Satellites for Geodesy. Geophysical Monograph Series, 115, 247-251. Washington, DC: AGU. https://doi.org/10.1029/GM015p0247

Schüler, T. (2001). On ground-based GPS Tropospheric Delay Estimation ( $\mathrm{PhD}$ dissertation). Universität der Bundeswehr, Munich. Retrieved 16 May 2018 from https://www.unibw.de/ IfG/Org/schriftenreihe/pdf-ordner/heft-73/heft-73.pdf

Warburton, J. (2010, October 21). Tropospheric error bounding: nominal and anomalous nominal tropospheric conditions. parameter calculation and consistency. Paper presented at CAAC Team Discussions. Retrieved 16 May 2018 from http://laas.tc.faa.gov/documents/CAAC/CAAC $\% 2011 \% 20$ Tropospheric\%20Threat.pdf

\section{APPENDIX}

\section{Notations}

\section{Variables and functions}

$P R_{\text {cor }}[m]$ - the corrected pseudo-range;

$P_{C S C}[m]$ - the smoothed pseudo-range (obtained by the airborne subsystem from the code pseudo-range and carrier phase measurements);

PRC $[m]$ - the pseudo-range correction (provided by the ground subsystem);

$R R C\left[\frac{m}{s}\right]$ - the pseudo-range correction rate (provided by the ground subsystem);

$t[s]$ - current time (time of pseudo-range measurement by airborne subsystem);

$t z \_$count $[s]$ - time of applicability derived from the modified Z-count (time of pseudo-range measurement by ground subsystem);

$c=2.9979 \cdot 10^{8}\left[\frac{m}{s}\right]$ - the speed of light in a vacuum;

$\left(\Delta t_{s v}\right)_{L 1}[s]$ - the satellite PRN code phase offset (calculated by airborne subsystem);

$T C[m]$ - the residual tropospheric error for a given satellite (calculated by the airborne subsystem), in meters;

$N_{R}\left[\frac{m m}{k m}\right]$ - troposphere refraction index, transmitted by the ground subsystem (Type 2 message), in millimeters per kilometer;
$N_{d}\left[\frac{m m}{k m}\right]-$ dry component of troposphere refraction index;

$N_{w}\left[\frac{\mathrm{mm}}{\mathrm{km}}\right]$ - wet component of troposphere refraction index;

$\Theta[$ rad $]$ - elevation angle of the satellite;

$h_{0}[m]$ - troposphere scale height, transmitted by the ground subsystem (Type 2 message), in meters;

$h_{d}[m]$ - dry component of troposphere scale height for ground subsystem altitude;

$h_{w}[m]$ - wet component of troposphere scale height for ground subsystem altitude;

$h[m]$ - the height of the ground subsystem above the mean sea level, in meters;

$\Delta h[m]$ - difference in altitude between airborne and ground subsystems, in meters;

$H[m]$ - the length of the signal path through the troposphere in zenith direction, in meters;

$d H$ - differential change in height;

$\Delta Z[m]$ - the troposphere zenith delay, in meters;

$Z_{d}[m]$ - dry component of the troposphere zenith delay;

$Z_{w}[m]$ - wet component of the troposphere zenith delay; 
$P_{0}[h P a]$ - the pressure at the sea level;

$P(H)$ - pressure as a function from height;

$P[h P a]$ - the pressure at the ground subsystem level;

$d P$ - differential change in pressure;

$T_{0}[K]$ - absolute temperature at the mean sea level;

$T(H)$ - temperature as a function from height;

$T[K]$ - the temperature at the ground subsystem level;

$T^{*}=273.15[K]-$ the temperature of water freezing;

$e_{0}[h P a]$ - the partial pressure of water vapor at the mean sea level;

$e[h P a]$ - the partial pressure of water vapor at the ground subsystem level;

$e^{*}=6.11[h P a]$ - the particular pressure of water vapor at the temperature of water freezing;

$L=2.83 \cdot 10^{6}\left[\frac{\mathrm{J}}{\mathrm{kg}}\right]$ - residual heat of vapor creation above the flat water surface;

$k_{1}=77.64\left[\frac{K}{h P a}\right], k_{2}=3.718 \cdot 10^{5}\left[\frac{K^{2}}{h P a}\right]$ - experimentally defined coefficients;

$\mathrm{RH}_{0}$ - percentage of relative humidity at the sea level;

$R_{e}=461\left[\frac{J}{\hat{E} \cdot k g}\right]-$ the gas constant for water vapor;

$R_{d}=287.54\left[\frac{\mathrm{J}}{\mathrm{kg} \cdot \mathrm{K}}\right]-$ the specific gas constant of dry air;

$h_{t r, d}[m]$ - the height of troposphere dry component;

$h_{t r, w}[m]$ - the height of troposphere wet component;

$\varphi[\mathrm{rad}]$ - latitude of the ground subsystem;

DoY - day of the year;
Do $Y_{0}$ - the coldest day of the year; equals 28 for the northern semi sphere and 211 for the southern;

$\beta\left[\frac{K}{m}\right]$ - the temperature lapse rate (coefficient of temperature rate according to height);

$\lambda\left[\frac{h P a}{m}\right]-$ coefficient of water vapor partial pressure rate ac$g\left[\frac{m}{s^{2}}\right]$ - the gravity;

$\rho\left[\frac{k g}{m^{3}}\right]$ - the density of dry air;

$X_{R}, Y_{R}, Z_{R}[m]$ - the reference coordinates of the navigation receiver in ECEF frame;

$X_{S_{i}}, Y_{S_{i}}, Z_{S_{i}}[m]$ - the coordinates of the $i$-th navigation satellite in the ECEF frame;

$R_{i}[m]$ - the distance between receiver and the $i$-th navigation satellite;

$\varphi_{R}, \lambda_{R}[\mathrm{rad}]$ - the latitude and longitude of the navigation receiver in the ECEF frame;

$S, C$ - sine and cosine functions;

\section{Abbreviations}

ECEF - Earth Centered Earth Fixed;

ENU - East North Up;

DCM - Direction Cosine Matrix;

GNSS - Global Navigation Satellite System;

GBAS - Ground Based Augmentation System;

GLS - GNSS landing system;

PBN - Performance Based Navigation;

VHF - Very High Frequency;

VDB - VHF data broadcast. 